\section{ECONOMICAL IMAGING TECHNOLOGY}

Capturing a clear image of your patient's mouth with the lightweight intra-oral Cammy camera instantly enables the patient to see exactly what you see.

The Cammy's distinctive mini-head design enables you to access even the hardest to reach areas, helping identify cracks and find root canals. Connecting directly to your computer via a USB port, these images can be easily stored, retrieved and transmitted.

The easy to use, affordable digital dental radiography system Digirex uses state-of-theart CCD technology to provide you with high definition imaging for perfect $x$-rays, enabling faster diagnosis and eliminating the cost of chemicals and film.

Call Evident on 0500321111 or visit www.evident.co.uk.

Reader response number 55

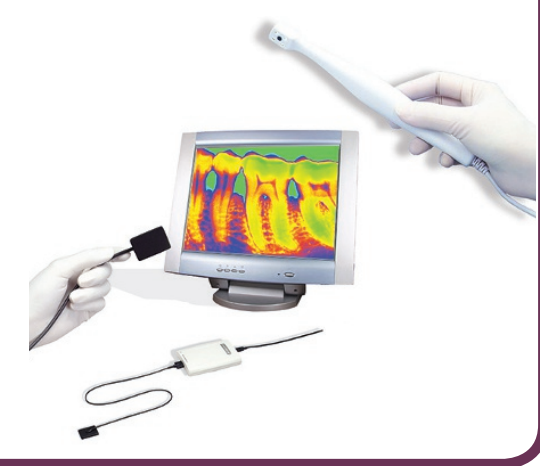

\section{GOLD STANDARD IN INSTRUMENTS}

Goldspeed is an exciting new range of handpieces

by Castellini that fulfil the most exacting

requirements of dentistry. They offer accuracy and comfort - vital for arduous procedures.

The merits of Goldspeed handpieces include:

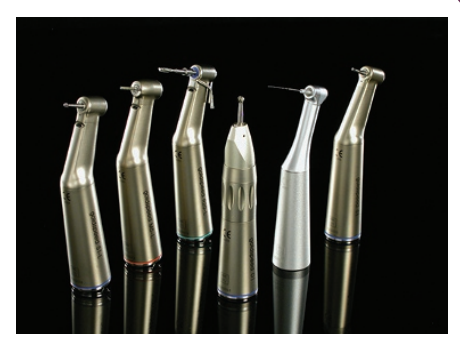

titanium heads and handgrips for strength and lightness; contra-angled for balance and manoeuvrability; high-intensity fibre optic lighting, for long-lasting, white illumination; viable for general, restorative, endodontic, prosthetic and surgical fields; and they are easily compatible with all ISO 3964 micromotor couplings.

Sanitation is also integral to the handpieces as they are fully autoclavable and include a device to prevent the retraction of contaminants.

For further information about the range of Castellini products call 08707560219 or visit www.castellini.com.

Reader response number 56

\section{IMPROVING PERIODONTAL HEALTH}

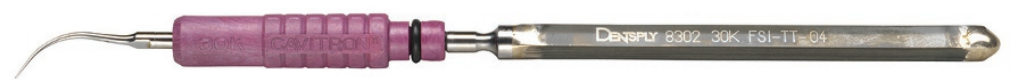

The Cavitron ultrasonic scaler system effectively removes subgingival biofilm to help improve periodontal health. The Cavitron can be used with the new THINsert for subgingival root surface debridement, and the SoftTip insert, which allows comprehensive scaling around titanium implants.

Oraqix is a non-injectable local anaesthetic designed for use in scaling and root planing. With an onset of just 30 seconds and a relatively short duration (20 minutes), it is both quick for the practitioner and short lasting for patient comfort.

Many hygienists like to conclude the treatment by hand, and Dentsply's

Flexichange range offers soft-grip silicone handles and the range of scalers, curettes and hoes all fit comfortably in the hand, minimising hand fatigue and improving grip and rotational control.

Telephone 08000723313 or visit www.dentsply.co.uk

Reader response number 57
ONLINE COURSE SUCCESS FOR DENTAL NURSES

King's College Hospital Dental Nurse

Education \& Training Centre (KCH DNETC)

- a rapidly growing and innovative element

of the King's Health Partners Dental Institute

- has recently developed an online course for dental nurses working towards the National

Examining Board for Dental Nurses (NEBDN)

National Certificate.

An initial pilot of the programme provided training for six dental nurses who successfully completed the course. To date five of the six participants have entered the NEBDN National Certificate examination and a $100 \%$ pass rate was achieved.

The second cohort of 20 students are already enrolled and participating online. Other online courses for dental nurses have already been developed and are available via the Dental Nurse Education \& Training Centre.

See www.kch.nhs.uk/dnetc/

Reader response number 58

\section{LOOKING FOR PEACE OF MIND?}

You look after your patients' health but how often do you think about your own?

That's the message from Income Protection specialist, dg mutual, who provides a regular tax-free income to self-employed professionals if they can't work due to sickness or injury.

dg mutual's immediate cover plan provides income from the first day of their illness or injury. And because members own the mutual society, they even receive a share of the profits when their policy finishes.

Sound good? Visit www.dgmutual.co.uk to find out more about Income Protection and how dg mutual paid out $99 \%$ of claims for the last two years running.

Reader response number 59

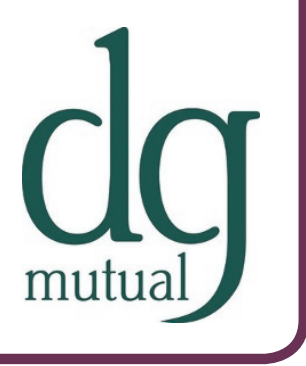

